\title{
Numerical Simulation and Experimental Study of Deep Bed Corn Drying Based on Water Potential
}

\author{
Zhe Liu, ${ }^{1}$ Zidan Wu, ${ }^{2}$ Xiaomeng Wang, ${ }^{1}$ Jia Song, ${ }^{1}$ and Wenfu Wu ${ }^{1}$ \\ ${ }^{1}$ College of Biological \& Agricultural Engineering, Jilin University, Changchun 130022, China \\ ${ }^{2}$ Academy of State Administration of Grain, Baiwanzhuang Street 11, Xicheng District, Beijing 100037, China \\ Correspondence should be addressed to Wenfu Wu; wwfzlb@126.com
}

Received 11 March 2015; Revised 8 June 2015; Accepted 10 June 2015

Academic Editor: Valentin Lychagin

Copyright (c) 2015 Zhe Liu et al. This is an open access article distributed under the Creative Commons Attribution License, which permits unrestricted use, distribution, and reproduction in any medium, provided the original work is properly cited.

\begin{abstract}
The concept and the model of water potential, which were widely used in agricultural field, have been proved to be beneficial in the application of vacuum drying model and have provided a new way to explore the grain drying model since being introduced to grain drying and storage fields. Aiming to overcome the shortcomings of traditional deep bed drying model, for instance, the application range of this method is narrow and such method does not apply to systems of which pressure would be an influential factor such as vacuum drying system in a way combining with water potential drying model. This study established a numerical simulation system of deep bed corn drying process which has been proved to be effective according to the results of numerical simulation and corresponding experimental investigation and has revealed that desorption and adsorption coexist in deep bed drying.
\end{abstract}

\section{Introduction}

Drying is one of the important parts in agricultural production [1]. It is an important research topic for how to effectively predict and control the drying process to ensure food quality after drying. However, drying is a complicated process involving simultaneous heat and mass transfer phenomena, and the essence is the moisture migration process. It is not only affected by material properties and medium parameters, but also has an important relationship with climate conditions and drying process. Therefore, the research on simulation of drying process has attracted many domestic and foreign scholars' attention in the frontier field of agricultural engineering science. The most common type of cereal dryers is the deep bed dryer, also known as fixed bed dryers [2,3]. Deep bed models for grain drying simulation can be classified as logarithmic, heat and mass balance, and partial differential equation [4]. The partial differential equation (PDE) model is more detailed, accurate, and valid for deep bed models for cereal drying simulation [5]. Since 1967, Bakker-Arkema et al. proposed a set of partial differential equations to describe grain drying process according to the basic theory of heat and mass transfer [6, 7]. In 1969, Spencer [8] derived a nonequilibrium model according to Bakker-Arkema but employed a different drying rate equation. The model was solved by a centered finite difference method. In order to test the model predictions, comparisons were made with the experimental work of Woodforde and Lawton [9] and Clark and Lamond $[10,11]$. Reasonable agreement has been obtained with the average moisture content, but the comparison of exit air dry bulb temperature was unsatisfactory. In 1982, Sharp [12] neglected accumulation terms from energy and mass balance equation in his model. He justified this simplification by reference to earlier work of Bakker-Arkema et al. and Spencer. In 1995, Sun et al. [13] developed a static bed drying model including rewetting and condensation effects. In this model, the energy accumulation terms from air energy balance equation were conserved. Comparisons between the predictions and measured results have shown that their model predictions correspond to the measured values within experimental errors. In 2002, Srivastava and John [14] developed a grain drying model and they proposed a solution by an implicit numerical scheme and Runge-Kutta method to predict air humidity and temperature as well as grain temperature evolution with variation of bed height during drying. In this model, the accumulation terms from 
mass and energy balance were kept but their results were not compared with experimental data. In above models, the impact of pressure in the drying process was not considered; that is, above models were only suitable for the analysis of the drying process under atmospheric pressure but were not suitable for vacuum drying system which included the influence of pressure factor.

Water potential is one of the important applications of the concept of chemical potential in agriculture and biology. The concept of water potential was proposed by our country scholars Tang and Wang on the basis of the chemical potential in 1941 [15] and thus was widely used in foreign countries since the 1950s and in China after the 70s. In 2003, water potential theory was applied to the moisture migration model in the corn drying process by $\mathrm{Wu}$ for the first time [16]. In 2006, water potential theory was applied to analyze heat and mass transfer in corn grains internal in vacuum drying process, and the model was established in corn low temperature vacuum drying process based on water potential by Yin et al. [17-19]. Xu et al. established the rate model of moisture migration in paddy rice vacuum drying process based on analysis of the water potential theory [20]. In 2002, water potential model analytical solution was solved by Laplasse by Yang and its application was more convenient [21].

In this paper, water potential drying model and the traditional deep bed drying model were integrated. An effective new simulation method of deep bed drying process was found and thus could overcome the shortcoming that the application range of the traditional model is narrow and thus is not suitable for vacuum drying system which included the influence of pressure factor. And this model can be used generally. A numerical simulation system of deep bed drying grain was developed by the combination of MATLAB and LabVIEW, and the results of numerical simulation and the tests were contrasted.

\section{Mathematical Modelling}

2.1. The Relationship between Changes of Water Potential and Drying Rate in Drying Process. Water potential is widely used in agriculture and biology; it can fully reflect the moisture migration process. The expression of water potential is as follows [17]:

$$
\phi=\frac{R T}{V_{w}} \ln a_{w}+\left(p-p_{0}\right)+\rho g h .
$$

In the formula, the first is referred to as the osmotic potential, the second as pressure potential, and third as gravitational potential [17].

During the drying process, the exchange between grains and the surrounding air water is carried out by particles in the epidermis. The skin of particles which has internal porous structure has a certain thickness and pore [16].

Ignoring the effect of pressure and gravity, the water potential of inner cereal grains is expressed as

$$
\varphi_{\text {in }}=\frac{R T}{V_{w}} \ln \left(r_{s} \cdot \frac{M}{M_{s}}\right),
$$

where $r_{s}$ is water activity coefficient of grain internal, and the calculation formula of $r_{s}$ is shown as follows:

$$
r_{s}=\frac{M_{s} \cdot \mathrm{RH}}{M_{e}}
$$

Similarly, outside of the cereal grains, air water potential is defined as

$$
\begin{aligned}
\varphi_{a} & =\frac{R T}{V_{w}} \ln \left(\frac{e}{e_{s}}\right)=\frac{R T}{V_{w}} \ln (\mathrm{RH}), \\
\varphi_{T} & =\varphi_{a}-\varphi_{\text {in }}=\frac{R T}{V_{w}} \ln \left(\frac{M_{s} \cdot \mathrm{RH}}{r_{s} \cdot M}\right),
\end{aligned}
$$

where $\varphi_{T}$ is moisture migration potential.

For $\varphi_{T}<0$, internal moisture is migrated outside. This is the analytical process of granular material.

For $\varphi_{T}=0$, internal moisture and external moisture are balanced. Granular material internal moisture is equilibrium moisture. In this case, grain is under equilibrium.

For $\varphi_{T}>0$, external moisture is migrated inward. This is the moisture absorption process of granular material.

Therefore, we can think that granular material moisture migration rate $(d M / d t)$ depends on the moisture migration potential:

$$
\frac{d M}{d t}=f\left(\varphi_{T}\right)
$$

According to corn drying characteristic curve [22], there appears to be a linear relationship between the average humidity of corn and drying time in most of the area. For convenient calculation, we assumed that there is a linear correlation between $d M / d t$ and $\varphi_{T}$, and differential equation of $d M / d t$ can be derived as follows:

$$
\begin{aligned}
\frac{d M}{d t} & =k \cdot \varphi_{T}=k \cdot \frac{R T}{V_{w}} \ln \frac{M_{s} \cdot \mathrm{RH}}{r_{s} \cdot M}, \\
K & =k \cdot \frac{R}{V_{w}}, \\
M_{e} & =\frac{M_{s} \cdot \mathrm{RH}}{r_{s}},
\end{aligned}
$$

where $M_{e}$ is the equilibrium moisture content of corn under atmospheric pressure. Henderson equation is adopted as equilibrium moisture equation [23]. That is,

$$
M_{e}=\left[-\frac{\ln (1-\mathrm{RH})}{A(T+B)}\right]^{1 / n},
$$

where the coefficients $A, B, n$, and $\mathrm{RH}$ are given by the expressions: $A=8.654 \times 10^{-5}, B=49.81, n=1.8634$, and 


$$
\mathrm{RH}=\frac{1.626 H /(1+1.608 H) \times 10^{5}}{6892.4 \exp [54.633-12301.69 /(1.8 T+492)-5.169 \ln (1.8 T+492)]} .
$$

Therefore, (6) becomes

$$
\frac{d M}{d t}=K T \cdot \ln \frac{M_{e}}{M} .
$$

Applying the Taylor series expansion, we can obtain formula (13) from (11):

$$
\frac{d M}{d t}=K T \ln \left(1+\frac{M_{e}-M}{M}\right) \approx K T\left(\frac{M_{e}-M}{M}\right) .
$$

Applying the Runge-Kutta method of order 4 to solve formula (13), we can obtain formulas (14) (18). Therefore, formulas (14) (18) are the analytical solution of corn drying model based on water potential:

$$
\begin{aligned}
k_{1} & =K T \cdot \frac{M_{e}}{M_{i}}-K T, \\
k_{2} & =K T \cdot \frac{M_{e}}{M_{i}+0.05 k_{1}}-K T, \\
k_{3} & =K T \cdot \frac{M_{e}}{M_{i}+0.05 k_{2}}-K T, \\
k_{4} & =K T \cdot \frac{M_{e}}{M_{i}+0.1 k_{3}}-K T, \\
M_{i+1} & =M_{i}+0.0167\left(k_{1}+2 k_{2}+2 k_{3}+k_{4}\right),
\end{aligned}
$$

where the model coefficient $K$ is related to temperature and vacuum degree. In this paper simulation and experiment were studied under atmospheric pressure, so the influence of the pressure gradient is ignored. That is, the $K$ value is only related to temperature. The $100 \mathrm{~g}$ and uniform size corn samples were selected which initial moisture content was $20 \%$. The corn sample was put into the sieve bowl and the weight was recorded. The temperature was set up under the condition of normal atmospheric pressure, and thus the temperature drying was selected at $40^{\circ} \mathrm{C}, 45^{\circ} \mathrm{C}, 50^{\circ} \mathrm{C}, 55^{\circ} \mathrm{C}$, $60^{\circ} \mathrm{C}$, and $65^{\circ} \mathrm{C}$, respectively. The corn samples were placed in the drying oven when the temperature reached equilibrium. The weigh was recorded per 1 hour, which was converted into the wet basis moisture content of corn. The test was not stopped until the corn quality reached the equilibrium state. The equilibrium state can be considered as no more than $0.2 \mathrm{~g}$ mass difference between the former and latter halfhour weigh and thus can be considered to reach equilibrium moisture content of corn. The model parameters of (12) (17) were substituted by test datum, and then the value of $K$ can be solved. The value of $K$ and the temperature were regression analyzed, and then the model of $K$ about hot air temperature was obtained:

$$
K=9.0833 \times 10^{-5} T^{2}+2.9333 \times 10^{-3} T .
$$

2.2. Partial Differential Drying Model during Drying Process. Brooker et al. proposed a theoretical model which is based on heat and mass transfer theory for the drying process. That model describes the grain drying process with a series of partial differential equations, including changes of grain temperature $\theta$, medium temperature $T$, and humidity of the air $H$ [24]. The corn drying model based on the heat and mass transfer is very complex, and, in order to simplify the drying model and reduce the complexity and computational time, the proposed fixed bed drying model is based on the following assumptions $[24,25]$ :

(1) The volume shrinkage is negligible during the drying process.

(2) The temperature gradients within individual particles are negligible.

(3) The bin walls are adiabatic with negligible heat capacity.

(4) The particle-to-particle heat conduction is negligible.

(5) The air flow and grain flow are plug flow.

(6) An accurate thin layer equation is known.

2.2.1. Mass Balance Equation. The amount of grain moisture evaporation is equal to wet air moisture obtainment. Mass balance equation is established to solve humidity of the hot air $H$ at the outlet.

$$
\frac{\partial H}{\partial x}=-\frac{\rho_{p}}{G_{a}} \frac{\partial \bar{M}}{\partial t}
$$

2.2.2. Balance on the Enthalpy of Grain. The heat enthalpy transmitted from air to the grain by means of convective heat exchange is equal to the enthalpy required for water evaporation in the grain kernels over the control volume and for heating the water vapor extracted from the kernels and heating the kernels. Heat balance equation for obtaining the temperature of the thin layer kernels is shown as follows:

$$
\frac{\partial \theta}{\partial t}=\frac{h_{a}(T-\theta)}{\rho_{p} C_{p}+\rho_{p} C_{w} \bar{M}}-\frac{h_{f g}+(T-\theta) C_{v}}{\rho_{p} C_{p}+\rho_{p} C_{w} \bar{M}} G_{a} \frac{\partial H}{\partial x}
$$

where the volumetric heat transfer coefficient $\left(h_{a}\right)$ for corn in a bed was calculated using Barker's equation [26]:

$$
h_{a}=\alpha C_{a} G_{a}\left(\frac{2 r_{0} G_{a}}{\mu_{a}}\right)^{\beta} \cdot a_{s}
$$

where $\alpha$ and $\beta$ are constants ( $\alpha=0.2755$ and $\beta=-0.34$ ), $r_{0}$ is the equivalent particle radius equal to $0.008 \mathrm{~m}$ for corn, and 
TABle 1: Properties of corn.

\begin{tabular}{lll}
\hline Property & Unit & Expression \\
\hline$C_{p}$ & $\mathrm{KJ} \cdot(\mathrm{Kg} \cdot \mathrm{K})^{-1}$ & $C_{p}=1.465+0.0355 M_{d}$ \\
& & $\rho_{p}=a_{1}-a_{2} M+a_{3} M^{2}$, \\
$\rho_{p}$ & $\mathrm{Kg} \cdot \mathrm{m}^{-3}$ & $a_{1}=1086.3, a_{2}=2.971 \times 10^{3}$, \\
& & $a_{3}=4.81 \times 10^{3}$ \\
$a_{s}$ & $\mathrm{~m}^{2} \cdot \mathrm{m}^{-3}$ & $a_{s}=784$ \\
$r_{0}$ & $\mathrm{~m}$ & $r_{0}=0.008$ \\
\hline
\end{tabular}

TABLE 2: Thermodynamic equations.

\begin{tabular}{lll}
\hline Property & Unit & Expression \\
\hline$C_{a}$ & $\mathrm{~J} \cdot\left(\mathrm{Kg} \cdot{ }^{\circ} \mathrm{C}\right)^{-1}$ & $C_{a}=1003.4+0.178 T$ \\
$C_{v}$ & $\mathrm{~J} \cdot\left(\mathrm{Kg} \cdot{ }^{\circ} \mathrm{C}\right)^{-1}$ & $C_{v}=1859.0+0.236 T$ \\
$C_{w}$ & $\mathrm{~J} \cdot\left(\mathrm{Kg}^{\circ} \mathrm{C}\right)^{-1}$ & $C_{w}=4.2 \times 10^{3}$ \\
$h_{f g}$ & $\mathrm{~J} \cdot \mathrm{Kg}^{-1}$ & $h_{f g}=(1094-0.57 \theta)\left(1+4.35 e^{-28.25 M}\right)$ \\
\hline
\end{tabular}

$a_{s}$ is the specific surface area of corm equal to $784 \mathrm{~m}^{2} / \mathrm{m}^{3} \cdot \mu_{a}$ is air viscosity:

$$
\begin{aligned}
\mu_{a}= & 1.691 \times 10^{-5}+4.987 \times 10^{-8} T-3.187 \\
& \times 10^{-11} T^{2}+1.319 \times 10^{-14} T^{3} .
\end{aligned}
$$

2.2.3. Balance on the Enthalpy of Air. Convection heat of transfer process is equal to the difference of enthalpy before and after air entering the thin layer of grain, plus the enthalpy change of the air between kernels in time step. In order to figure out hot air temperature $T$ at a thin layer outlet, heat transfer balance can be established as follows:

$$
\frac{\partial T}{\partial x}=\frac{-h_{a}}{G_{a} C_{a}+G_{a} \cdot H \cdot C_{v}}(T-\theta) .
$$

Initial and boundary conditions for (12), (13), and (15) are $T(0, t)=T_{0}, \theta(x, 0)=\theta_{0}, H(0, t)=H_{0}$, and $M(x, 0)=M_{0}$.

\subsection{Required Equations}

2.3.1. Properties of Corn. Corn with different varieties and moisture content has different characteristics during the drying process. Equations are listed in Table 1 to get properties of corn $[23,27]$.

2.3.2. Thermodynamic Equations. To solve the model some physical properties of the air-vapor mixture are required. These can be determined by proper thermodynamical equations relating desired properties to known operational parameters. These equations are listed in Table 2 [23].

Above all kinds of representative significance of symbols are shown in Nomenclature.
Forward difference method is used to solve the above four differential equations, and discrete equations obtained are

$$
\begin{aligned}
\frac{H_{j}^{n}-H_{j}^{n-1}}{\tau}= & -\frac{\rho_{p}}{G_{a}} \frac{M_{j}^{n}-M_{j-1}^{n}}{2 h}, \\
\frac{\theta_{j}^{n}-\theta_{j-1}^{n}}{h}= & \frac{h_{a}\left(T_{j}^{n-1}-\theta_{j-1}^{n}\right)}{\rho_{p} C_{p}+\rho_{p} C_{w} M_{j-1}^{n}} \\
& -\frac{h_{f g}+\left(T_{j}^{n}-\theta_{j-1}^{n}\right) C_{v}}{\rho_{p} C_{p}+\rho_{p} M_{j-1}^{n} C_{w}} G_{a} \frac{H_{j}^{n}-H_{j}^{n-1}}{\tau}, \\
\frac{T_{j}^{n}-T_{j}^{n-1}}{\tau}= & \frac{-h_{a}}{G_{a} C_{a}+G_{a} H_{j}^{n} C_{v}}\left(T_{j}^{n-1}-\theta_{j-1}^{n}\right) .
\end{aligned}
$$

\section{Computer Simulation Method and Program}

3.1. Drying Simulation Method [14]. Consider the following:

(1) Divide deep grain bed into several thin layers (see Figure 1).

(2) Divide drying time into smaller time intervals.

(3) The initial moisture of the grain and air temperature $T_{0}$ and air humidity $H_{0}$ before hot air through the first thin layer are known. Therefore, after a certain time, the grain moisture content of the first layer can be determined using water potential equation after drying time step.

(4) Hot air humidity content of thin layer outlet is obtained by mass balance equations.

(5) Grain temperature $\theta$ of thin layer and hot air temperature $T$ of thin layer outlet are obtained by using the heat balance equation after drying time step.

(6) In order to obtain grain moisture content and temperature of the second thin layer and the hot air parameters of the third thin layer inlet after time step, hot air parameters of the first thin layer outlet are considered as inlet conditions of the second layer and then steps (3) to (5) are repeated. And that is continued until all thin layers.

(7) Time is increased step; then the above steps are repeated until unit exports.

3.2. Simulation Program. MATLAB was applied to numerical calculation of partial differential model in deep bed drying process, and call MATLAB file in LabVIEW to display its simulation results [28]. The flow chart of using MATLAB for numerical calculation of partial differential model is shown in Figure 2. The interactive interface of deep fixed bed drying numerical simulation system based on LabVIEW is depicted in Figure 3.

As seen in data entry area of LabVIEW front panel, parameters needed in the calculation process are input, and LabVIEW passes parameters to MATLAB Script node for numerical calculation of partial differential model in it. 


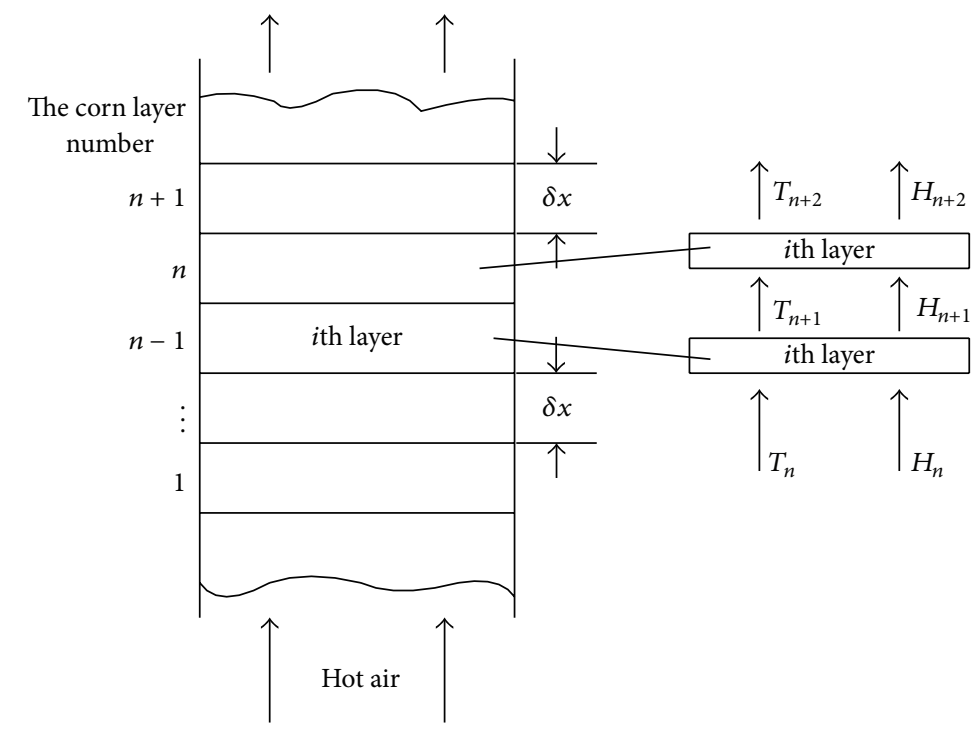

FIGURE 1: Schematic diagram of dividing deep layer into thin layers.

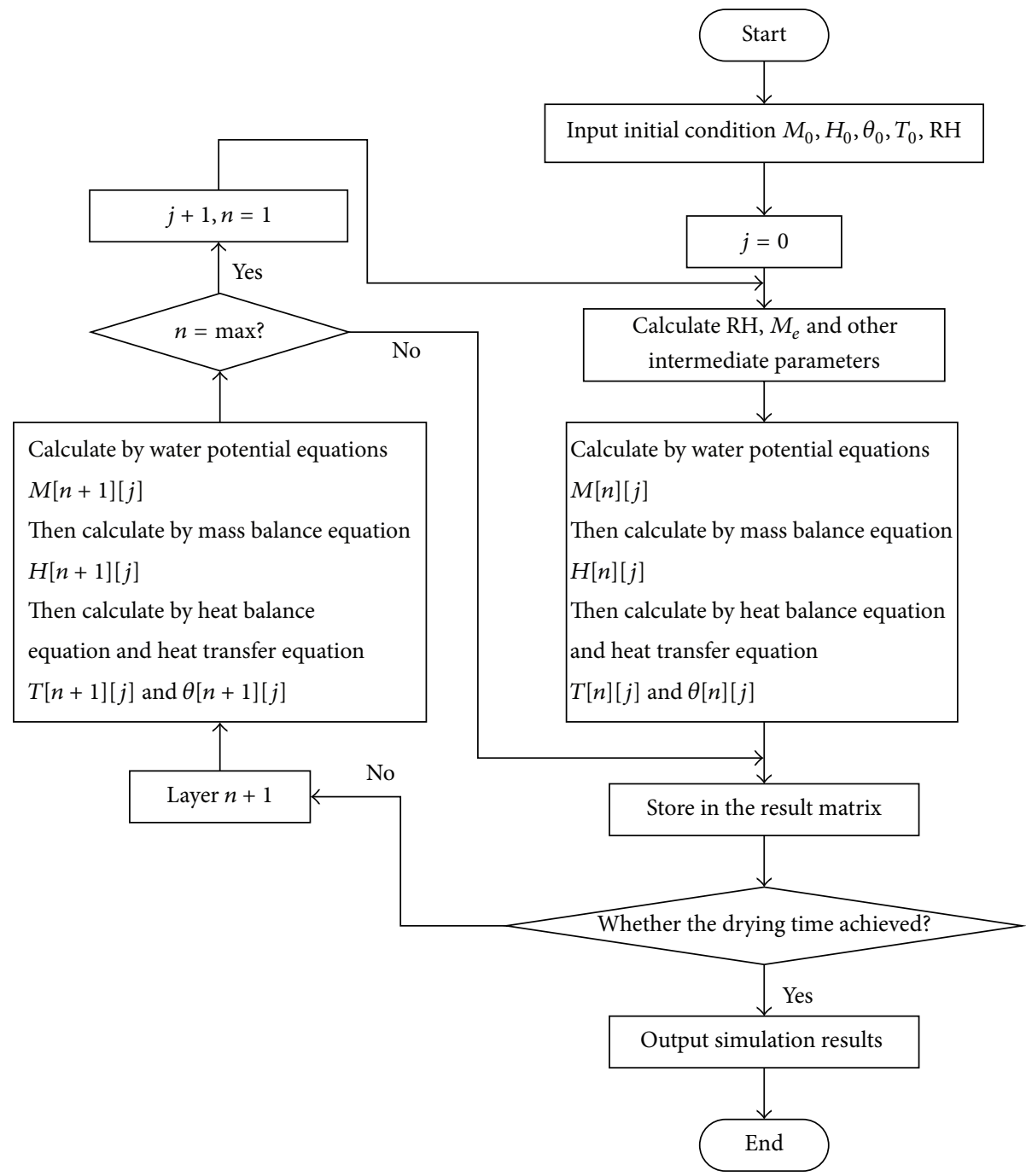

FIGURE 2: Flow chart of MATLAB numerical calculation process. 


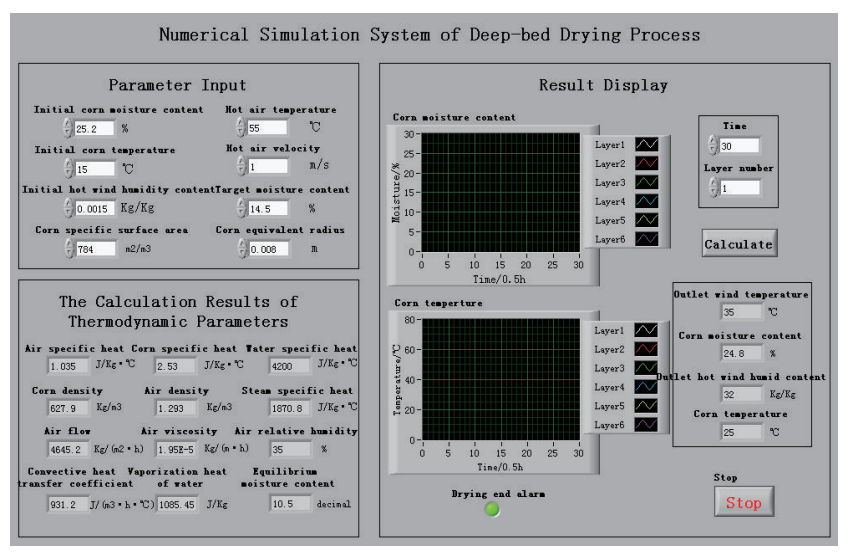

FIgURE 3: The interface of deep bed drying numerical simulation system based on LabVIEW.

TABLE 3: Simulation initial conditions.

\begin{tabular}{lc}
\hline Parameter & Value \\
\hline Initial corn moisture $(\%$ d.b. $)$ & $24.09,24.20,23.30$ \\
Initial corn temperature $\left({ }^{\circ} \mathrm{C}\right)$ & 12 \\
Inlet air temperature $\left({ }^{\circ} \mathrm{C}\right)$ & $45,55,65$ \\
Inlet air humidity content $\left(\mathrm{Kg} \cdot \mathrm{Kg}^{-1}\right)$ & 0.015 \\
Hot air velocity $(\mathrm{m} / \mathrm{s})$ & 0.4 \\
Time step $(\mathrm{h})$ & 0.5 \\
Bed depth $(\mathrm{m})$ & 0.3 \\
\hline
\end{tabular}

\section{Simulation Test of Grain Deep Bed Drying Process}

Simulation test was carried out by the above grain deep bed drying process simulation system. In the test the corn moisture content $M$, corn temperature $\theta$, hot air hot temperature $T$, and hot air humidity content $H$ at different depths of drying bed under different drying conditions were simulated.

Simulation initial conditions were displayed in Table 3 and they were input in LabVIEW interactive interface. After the start of the simulation, the simulation results under different drying conditions were output by this system.

\subsection{The Simulation Results Analysis of Corn Moisture Content} in Dry Basis. Computer simulation results of corn moisture content (\%d.b.) in 6 different layers under different initial conditions are shown in Figure 4. The moisture removal is slower as the bed layer height is higher. And the higher the hot air temperature is, the faster the rate of moisture removal is.

4.2. The Simulation Results Analysis of Hot Air Temperature. Computer simulation values of hot air temperature in 6 different layers under different initial conditions are presented in Figure 5. As the bed height increases, the air temperature reduces. And as time passes, the hot air temperature of each
TABLE 4: The Standard Error of Prediction (SEP) and the Maximum Error of Prediction (MEP) at different bed layers.

\begin{tabular}{|c|c|c|c|}
\hline Temperature & $\begin{array}{c}\text { Layer } \\
\text { number }\end{array}$ & $\begin{array}{l}\text { The Standard Error } \\
\text { of Prediction (SEP) }\end{array}$ & $\begin{array}{c}\text { The Maximum } \\
\text { Error of Prediction } \\
\text { (MEP) }\end{array}$ \\
\hline \multirow{6}{*}{$45^{\circ} \mathrm{C}$} & 1th & $1.25 \%$ & $3.91 \%$ \\
\hline & 2 th & $1.05 \%$ & $2.75 \%$ \\
\hline & 3 th & $1.54 \%$ & $3.75 \%$ \\
\hline & 4th & $1.23 \%$ & $3.06 \%$ \\
\hline & 5 th & $0.57 \%$ & $-1.02 \%$ \\
\hline & 6th & $0.36 \%$ & $0.96 \%$ \\
\hline \multirow{6}{*}{$55^{\circ} \mathrm{C}$} & 1th & $1.50 \%$ & $4.42 \%$ \\
\hline & 2 th & $0.85 \%$ & $2.79 \%$ \\
\hline & 3th & $1.54 \%$ & $4.41 \%$ \\
\hline & 4th & $1.01 \%$ & $2.57 \%$ \\
\hline & 5 th & $0.42 \%$ & $1.31 \%$ \\
\hline & 6th & $0.35 \%$ & $0.99 \%$ \\
\hline \multirow{6}{*}{$65^{\circ} \mathrm{C}$} & 1th & $0.74 \%$ & $1.12 \%$ \\
\hline & 2th & $0.99 \%$ & $2.07 \%$ \\
\hline & 3 th & $1.38 \%$ & $4.57 \%$ \\
\hline & 4 th & $0.88 \%$ & $1.39 \%$ \\
\hline & 5 th & $0.88 \%$ & $-1.89 \%$ \\
\hline & 6th & $-0.17 \%$ & $0.24 \%$ \\
\hline
\end{tabular}

thin layer outlet gradually increases, until all layers have reached the initial hot air temperature.

4.3. The Simulation Results Analysis of Corn Temperature. This information is particularly useful in determining the grain quality during drying process [29]. We can get the real grain temperature by computer simulation [30]. Computer simulation values of corn temperature under different initial conditions are shown in Figure 6. Being the same as hot air temperature trends, as drying proceeds, corn temperature gradually increases. However, since the energy given by hot air is provided for not only corn temperature rising but also evaporating of corn moisture [31]. Therefore corn temperature of each thin layer is lower than the temperature of the hot air flowing through it. Initially, the temperature of bed bottom rises rapidly, but the variation of corn temperature slows down with increasing distance from inlet section of the bed. As time goes up and corn becomes dryer, less heat is used for moisture evaporation and most of transferred heat from air to corn is served to increase the corn temperature, until corn temperature is equal to hot air temperature.

4.4. The Simulation Results Analysis of Hot Air Humidity Content. Computer simulation values of hot air moisture content determined by interaction of heat medium temperature and corn moisture in 6 different layers under different initial conditions are depicted in Figure 7. At the initial stage of drying, hot air moisture content increased, and the increase amount was more with the increase of layer. It 

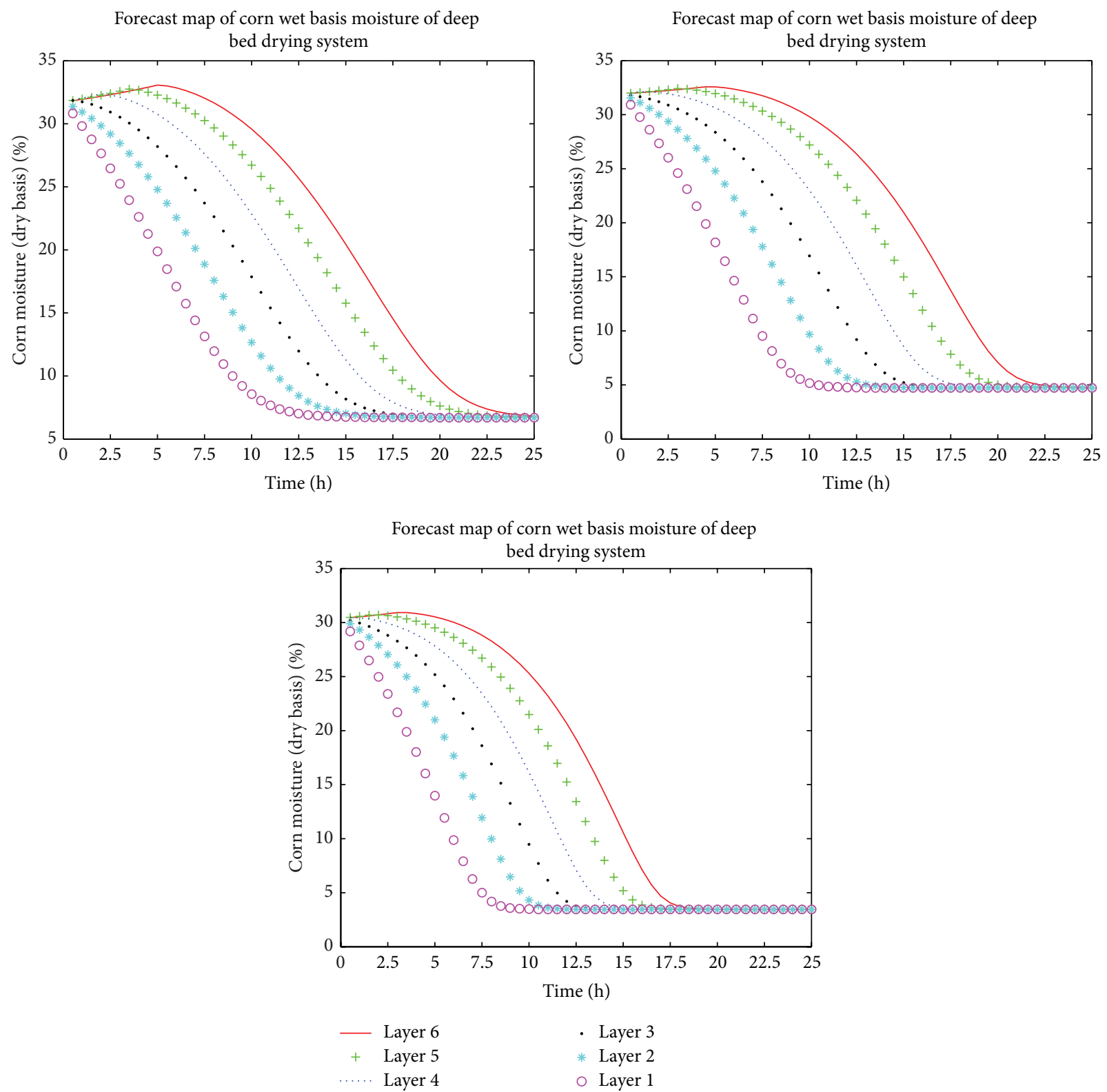

FIGURE 4: The variation of computer simulation values of corn moisture content (\%d.b.) with time in six different layers when air temperature was $45^{\circ} \mathrm{C}, 55^{\circ} \mathrm{C}$, and $65^{\circ} \mathrm{C}$ and the value of inlet air velocity was $0.4 \mathrm{~m} / \mathrm{s}$.

is due to adsorption phenomena that exist in upper corn at the initial stage of drying. That is, external moisture is migrated inward at that moment. The moisture of upper corn increases; therefore hot air moisture content which flows through the corn increases too. As time goes on, corn moisture is evaporated, and hot air humidity content from inlet section of thin layer decreases gradually, until it is equal to the initial hot air moisture content.

\section{Experimental Study of Grain Deep Bed Drying Process}

In order to verify the above computer simulation results, a deep fixed bed drying test for new harvest dent corn having a higher product in Jilin Province was conducted in laboratory. A schematic view of the experimental setup and apparatus is presented in Figure 8.

The deep fixed bed drying oven was refitted on the basis of a thin layer drying oven and consists of several thin layer drying test kits. These kits are stainless steel, inner diameters of $25 \mathrm{~cm}$ and $5 \mathrm{~cm}$ in height. Their bottom surfaces are circular mesh structure. The middle of each kit, $2.5 \mathrm{~cm}$ in height, was inserted a SHT11 digital temperature and humidity sensor. Humidity measurement range of the sensor is $0 \sim 100 \% \mathrm{RH}$ and temperature measurement range is $-40 \sim$ $+123.8^{\circ} \mathrm{C}$. Humidity measurement accuracy of the sensor is $\pm 3 \% \mathrm{RH}$ and temperature measurement accuracy is $\pm 0.4^{\circ} \mathrm{C}$. The test system consists of six thin layer drying test kits. 

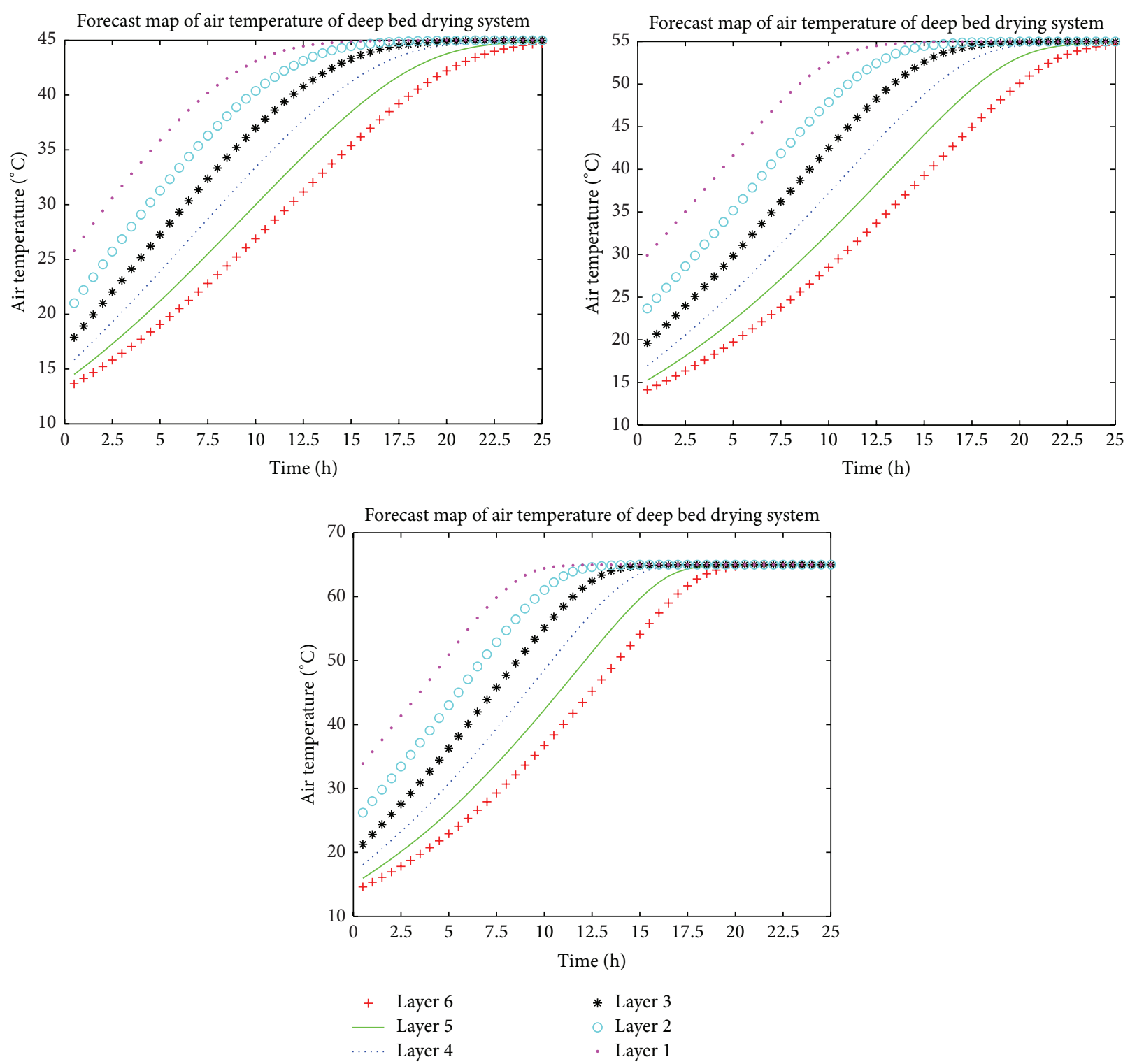

FIGURE 5: The variation of computer simulation values of hot air temperature with time in six different layers when air temperature was $45^{\circ} \mathrm{C}$, $55^{\circ} \mathrm{C}$, and $65^{\circ} \mathrm{C}$ and the value of inlet air velocity was $0.4 \mathrm{~m} / \mathrm{s}$.

Thin layer drying experiment boxes and sensor installation position are shown in Figure 9.

Temperature controller, having accuracy $\pm 1^{\circ} \mathrm{C}$, made automatic control of hot air temperature during the drying process. Drying temperature was selected at $45^{\circ} \mathrm{C}, 55^{\circ} \mathrm{C}$, and $65^{\circ} \mathrm{C}$, respectively. Drying air velocity was adjusted by the rotational speed of air blower and it was selected at $0.3 \mathrm{~m} / \mathrm{s}$, $0.4 \mathrm{~m} / \mathrm{s}$, and $0.5 \mathrm{~m} / \mathrm{s}$, respectively. During the experiment, the corn moisture content was calculated using the electronic weigh weight method. The calculation formula is as follows:

$$
M_{d}=1-\frac{m_{0}\left(1-M_{o}\right)}{m_{d}} .
$$

\section{Results and Analyses}

Figures 9-11 depict, under above initial conditions, the comparison between computer simulation and experimental values of corn moisture content (dry basis) in six thin layers during the drying process. As shown in these figures computer simulation and experimental values tend towards consistency. First half of the drying process, as bed height increases, the rate of moisture removal decreases gradually. That is, moisture removal from corn first contact with the hot air is the fastest, and surface corn furthest off the bed is the slowest. The results also show that there is a clear water gradient among six thin layers. That is the biggest drawback of the fixed bed drying. And this gradient increases as the temperature increases. As time passes, more 

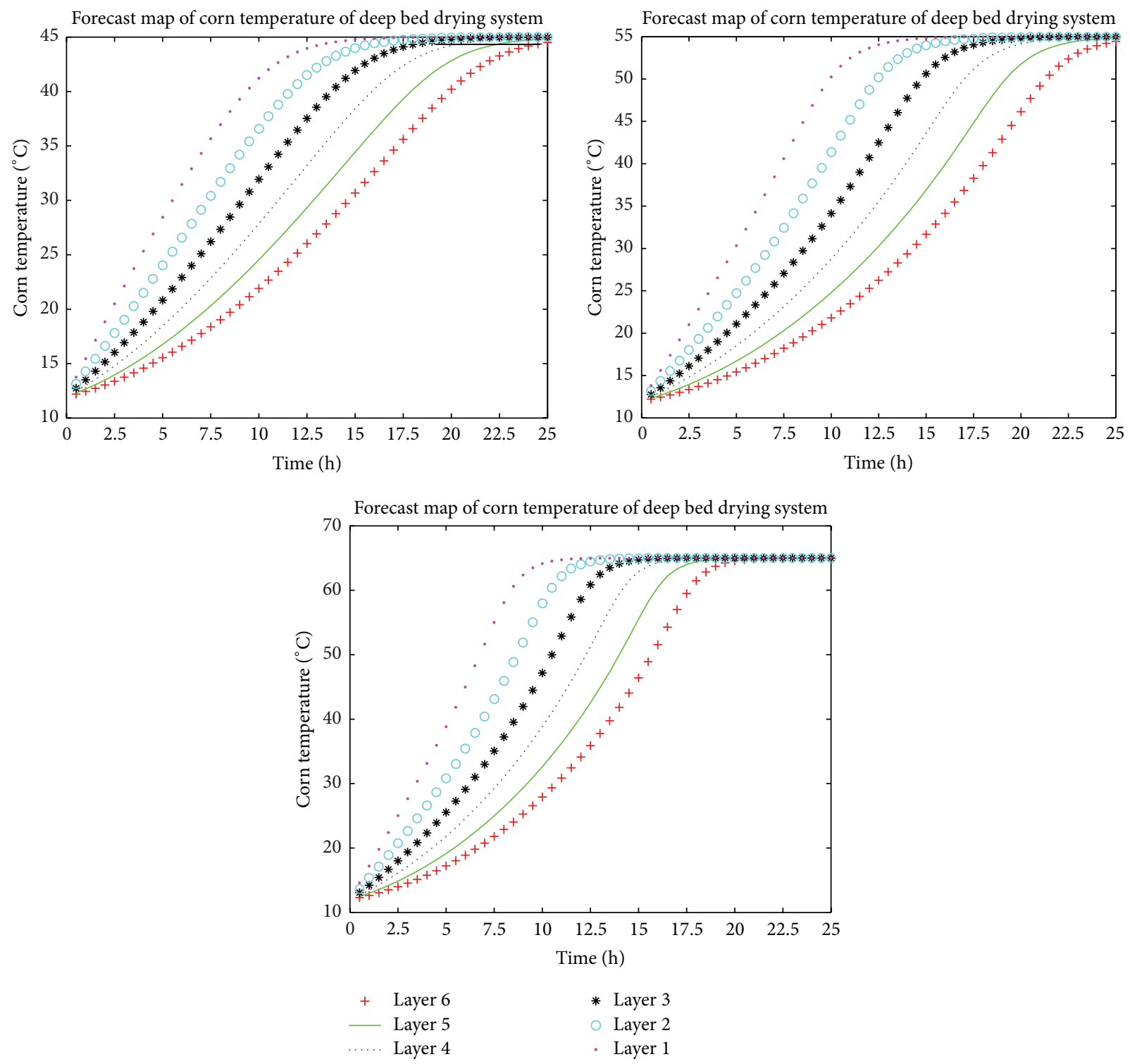

FIgURE 6: The variation of computer simulation values of corn temperature with time in six different layers when air temperature was $45^{\circ} \mathrm{C}$, $55^{\circ} \mathrm{C}$, and $65^{\circ} \mathrm{C}$ and the value of inlet air velocity was $0.4 \mathrm{~m} / \mathrm{s}$.

moisture is transferred from corn of lower bed. At this time, the rate of moisture transfer slows down gradually. The comparison between the simulation values and the experiment values was conducted by using 3 sigma criteria. The results are shown as follows: when air temperature is $45^{\circ} \mathrm{C}$, $55^{\circ} \mathrm{C}$, and $65^{\circ} \mathrm{C}$, the moisture residuals between simulation and experiment values are in $-0.817 \% \sim 1.552 \%,-0.671 \%$ $1.376 \%$, and $-1.019 \% \sim 1.032 \%$, respectively. At the same time, mean relative error (MRD) between the simulation values and the experiment values was calculated. The results are shown as follows: when air temperature is $45^{\circ} \mathrm{C}, 55^{\circ} \mathrm{C}$, and $65^{\circ} \mathrm{C}$, mean relative error (MRD) between the simulation values and the experiment values is $2.98 \%, 2.97 \%$, and $2.73 \%$, respectively. And the Standard Error of Prediction (SEP) and the Maximum Error of Prediction (MEP) at different bed layers were analyzed. The results are shown in Table 4.

It also can be seen in Figures 10-12 that the longer the drying time is, the greater the residual values are. Simulation moisture values are gradually higher than the test moisture values after corn moisture which is $14.5 \%$. This is due to the fact that, during the drying process, surface moisture removal is in front of internal moisture (unbound water in front of bound water), that is, easiness to hardness. When corn moisture is reduced to a certain extent, moisture removal is more difficult and the more energy is needed and thus was ignored in the process of simulation. However, drying is stopped when the moisture content drops to safe moisture $(14.5 \%)$. Thus we are not interested in moisture less than $14.5 \%$. 

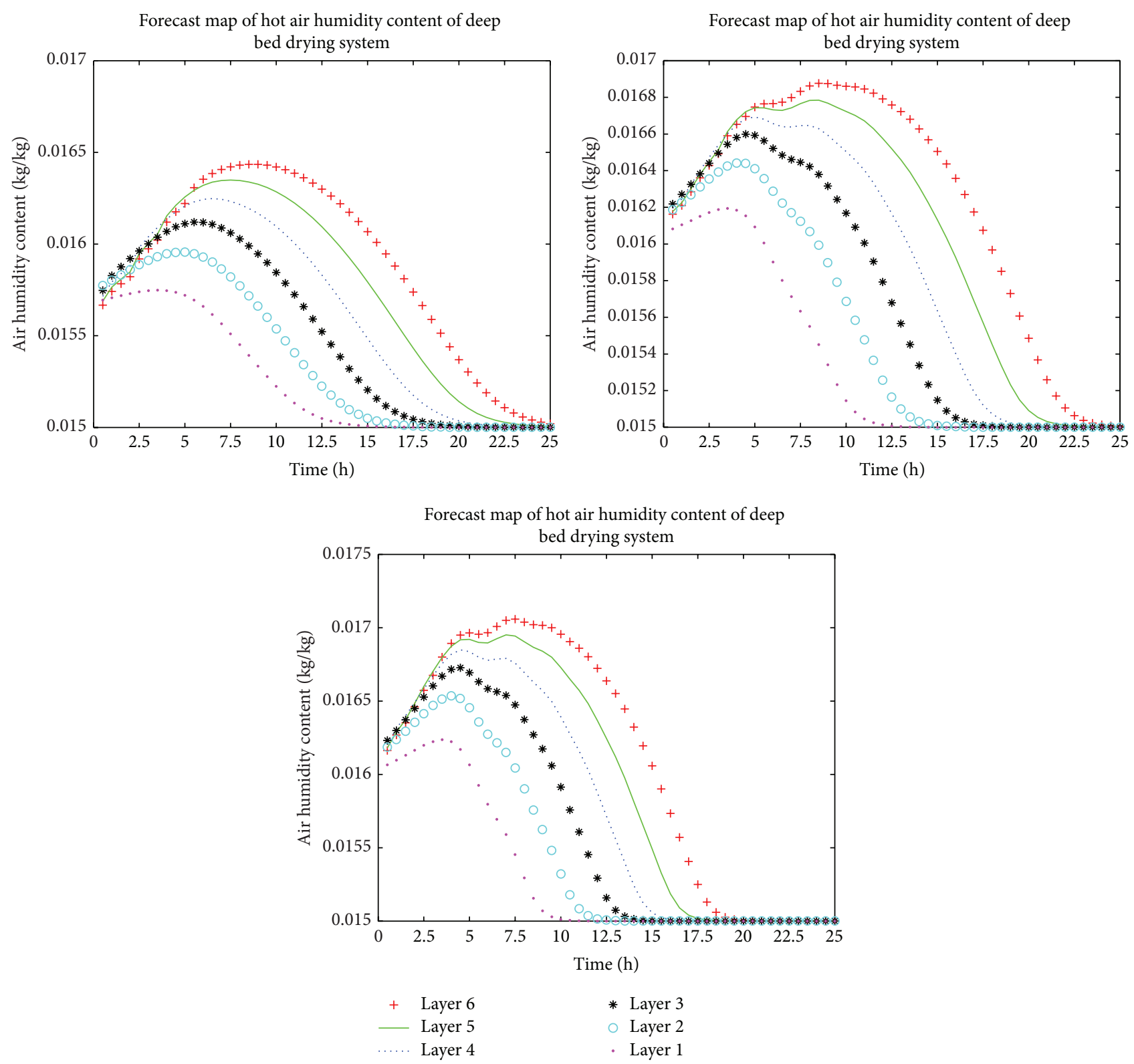

FiguRE 7: The variation of computer simulation values of hot air humidity with time in six different layers when air temperature was $45^{\circ} \mathrm{C}$, $55^{\circ} \mathrm{C}$, and $65^{\circ} \mathrm{C}$ and the value of inlet air velocity was $0.4 \mathrm{~m} / \mathrm{s}$.

Figures 10-12 also show that, at the beginning of drying, whether simulation values or experiment values, corn moisture in the fourth, fifth, and sixth layers is not falling but rising. It is due to that corn has hygroscopic capillary porous media [32]. Under certain conditions, they are capable of absorbing water vapor from ambient air or releasing water vapor. The ability to absorb or release water vapor is related to ambient air temperature and humidity [33]. If air relative humidity is larger during drying process, so that water potential of the atmospheric environment is higher than grains inside; thus air moisture will transfer to the inside of grains. At this time, the grain is in the adsorption process.
The drying process includes not only the desorption process, but also the adsorption process (the moisture ratio is bigger than 1).

\section{Conclusion}

This study clarifies the effects of various parameters in the drying process, based on water potential theory. The water potential and the traditional deep bed drying model were integrated. And the shortcomings that the application range of this method is narrow and such method does not apply 


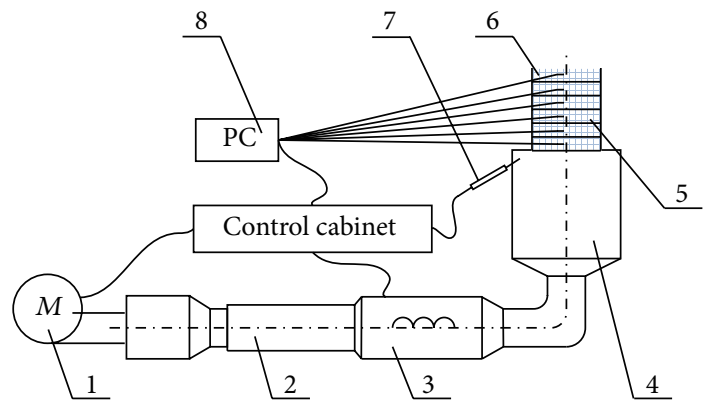
(1) Fan
(6) Temperature and humidity sensors
(2) Pipeline
(7) Temperature sensor
(3) Heating section
(8) Temperature and humidity
(4) Air mixing chamber data acquisition
(5) Thin layer drying test boxes

FIgURE 8: Fixed deep bed drying device.
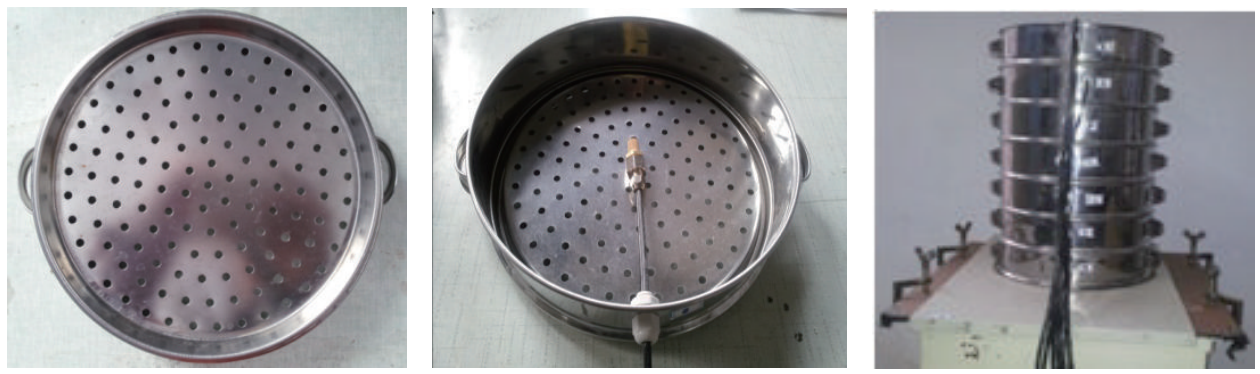

FIGURE 9: Thin layer drying experiment boxes and sensor installation position.

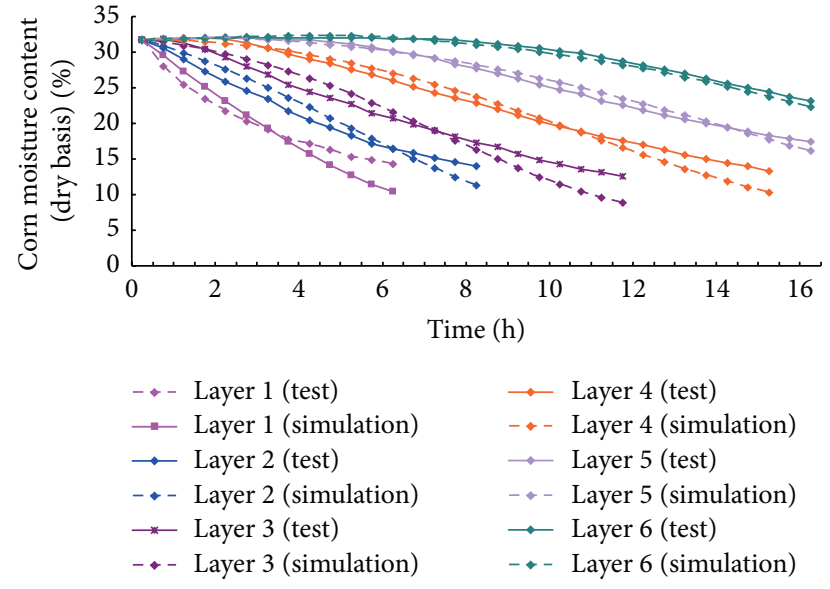

FIGURE 10: Comparison between simulation and experiment values of corn moisture content (dry basis) at $45^{\circ} \mathrm{C}$ when the value of inlet air velocity was $0.4 \mathrm{~m} / \mathrm{s}$.

to systems of which pressure would be an influential factor such as vacuum drying system were overcome. A numerical simulation system for deep bed grain drying was built based on the combination of MATLAB and LabVIEW. And the results have been confirmed in this study by comparing the simulation moisture contents with the experiment values. Conclusions are as follows:

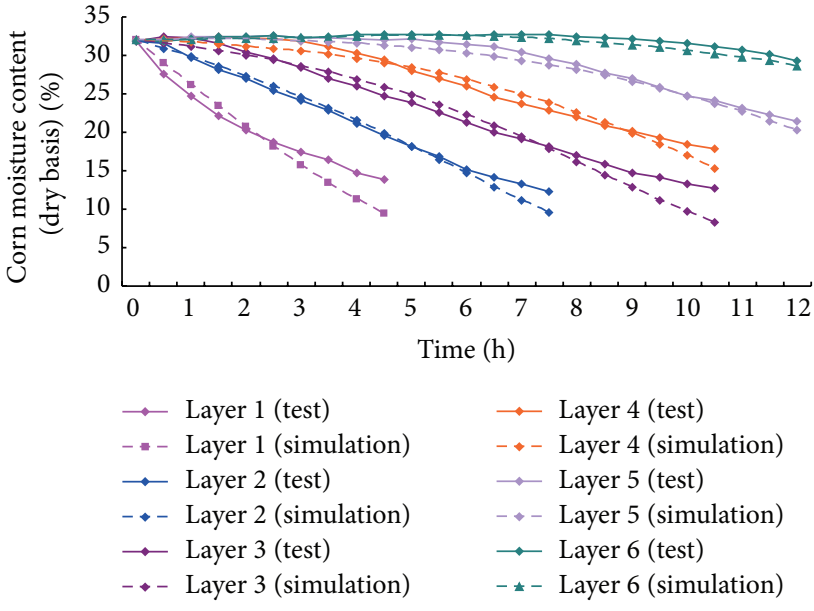

FIGURE 11: Comparison between simulation and experiment values of corn moisture content (dry basis) at $55^{\circ} \mathrm{C}$ when the value of inlet air velocity was $0.4 \mathrm{~m} / \mathrm{s}$.

(1) A new way to explore simulation of deep bad grain drying was proposed by combining water potential drying model and traditional deep bed drying models and overcoming the shortcomings of traditional deep bed drying model; for instance, the application range of this method is narrow and such method does 


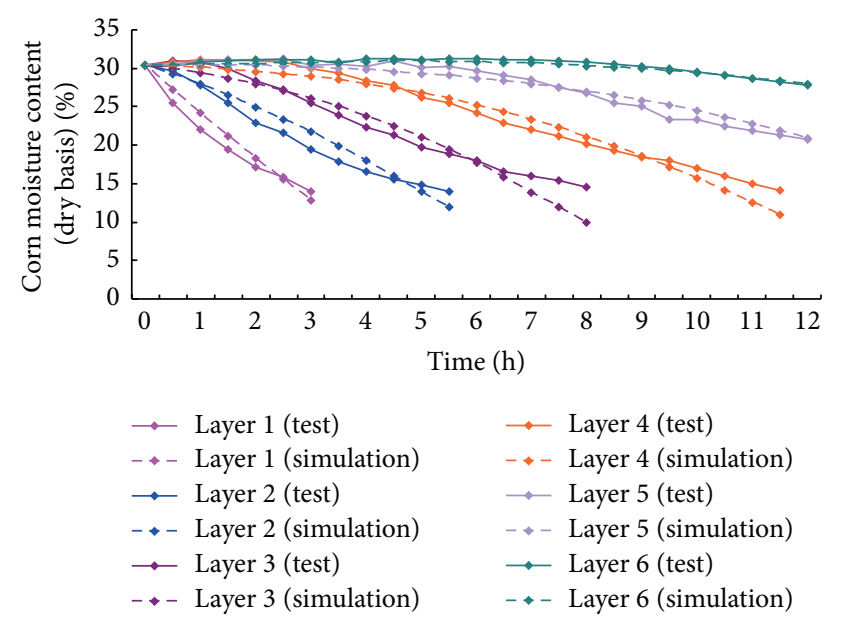

Figure 12: Comparison between simulation and experiment values of corn moisture content (dry basis) at $65^{\circ} \mathrm{C}$ when the value of inlet air velocity was $0.4 \mathrm{~m} / \mathrm{s}$.

not apply to systems of which pressure would be an influential factor such as vacuum drying system in a way combining with water potential drying model.

(2) A numerical simulation system for deep bed grain drying was developed by applying MATLAB and LabVIEW. The tests were conducted. Corn moisture content $M$ and temperature $\theta$, drying medium temperature $T$, and humidity content $H$ in six different layers under different initial conditions were calculated and analyzed. Better simulation results and prediction results were obtained.

(3) Corn deep bed drying experiment verified the correctness of the computer simulation results, showing that it is an effective new method to explore simulation for deep bed grain drying. When air temperature is $45^{\circ} \mathrm{C}, 55^{\circ} \mathrm{C}$, and $65^{\circ} \mathrm{C}$, the moisture residuals between simulation and experiment values is in $-0.817 \% \sim 1.552 \%,-0.671 \% \sim 1.376 \%$, and $-1.019 \%$ $1.032 \%$, respectively. When air temperature is $45^{\circ} \mathrm{C}$, $55^{\circ} \mathrm{C}$, and $65^{\circ} \mathrm{C}$, the mean relative error (MRD) between the simulation values and the experiment values is $2.98 \%, 2.97 \%$, and $2.73 \%$, respectively.

(4) In this study, the phenomenon in which desorption and adsorption coexist in deep bed drying process was revealed.

\section{Nomenclature}

$\varphi$ : Water potential, Mpa

$T_{K}$ : Absolute temperature, $\mathrm{K}$

$a_{w}$ : Water activity, decimal

$p_{0}$ : Atmospheric pressure, $\mathrm{Mpa}$

$M_{s}$ : Grain internal saturated moisture content (db), decimal

$e$ : Vapor pressure of the air, $\mathrm{Pa}$ $e_{s}$ : Saturated vapor pressure of the air, $\mathrm{Pa}$

T: $\quad$ Hot air temperature, ${ }^{\circ} \mathrm{C}$

$\theta: \quad$ Corn temperature, ${ }^{\circ} \mathrm{C}$

$\rho_{p}:$ Corn density, $\mathrm{Kg} \cdot \mathrm{m}^{-3}$

$C_{w}$ : Specific heat capacity of water, $\mathrm{J} \cdot\left(\mathrm{Kg} \cdot{ }^{\circ} \mathrm{C}\right)^{-1}$

$C_{p}$ : Specific heat capacity of dry corn, J · $(\mathrm{Kg} \cdot$ $\left.{ }^{\circ} \mathrm{C}\right)^{-1}$

$C_{a}$ : Specific heat capacity of dry air, $\mathrm{J} \cdot\left(\mathrm{Kg} \cdot{ }^{\circ} \mathrm{C}\right)^{-1}$

$h_{f g}$ : Latent heat of vaporization of water, $\mathrm{J} \cdot \mathrm{Kg}^{-1}$

RH: Air relative humidity, decimal

$\mu_{a}:$ Air viscosity, $\mathrm{Kg} \cdot(\mathrm{m} \cdot \mathrm{h})^{-1}$

$\rho_{a}:$ Air density, $\mathrm{Kg} \cdot \mathrm{m}^{-3}$

$M_{0}$ : Initial corn moisture content, decimal

$\theta_{0}$ : Initial corn temperature, ${ }^{\circ} \mathrm{C}$

$M_{d}$ : Corn moisture content (wet basis), \%

$m_{0}$ : Initial corn weight in the thin layer box, $\mathrm{Kg}$

$R: \quad$ Universal gas constant, $\mathrm{Pa} \cdot \mathrm{m}^{3} \cdot(\mathrm{mol} \cdot \mathrm{K})^{-1}$

$V_{w}$ : Partial molar volume of water, $\mathrm{m}^{3} \cdot \mathrm{mol}^{-1}$

p: $\quad$ Pressure, Mpa

$\varphi_{\text {in }}$ : Grain internal water potential, Mpa

$\varphi_{T}$ : The water potential of environmental atmosphere, Mpa

$r_{s}$ : Grain internal water activity coefficient, decimal

$\varphi_{a}:$ Microenvironment water potential, Mpa

$H$ : Hot air humidity content, $\mathrm{Kg} \cdot \mathrm{Kg}^{-1}$

$M$ : Corn average moisture content (db), decimal

$M_{e}$ : Corn equilibrium moisture content $(\mathrm{db})$, decimal

$G_{a}:$ Mass flow rate of air, $\mathrm{Kg} \cdot\left(\mathrm{m}^{2} \cdot \mathrm{h}\right)^{-1}$

$C_{v}$ : Specific heat capacity of water vapor, $\mathrm{J} \cdot(\mathrm{Kg}$. $\left.{ }^{\circ} \mathrm{C}\right)^{-1}$

$a_{s}$ : Corn particle surface area/unit bed volume, $\mathrm{m}^{2} \cdot \mathrm{m}^{-3}$

$r_{0}:$ Equivalent particle radius of corn, $\mathrm{m}$

$h_{a}$ : Volumetric convective heat transfer coefficient, $\mathrm{J} \cdot\left(\mathrm{m}^{3} \cdot \mathrm{h} \cdot{ }^{\circ} \mathrm{C}\right)^{-1}$

$x$ : Corn deep bed height coordinate, $\mathrm{m}$

$t$ : Drying tine, min

$T_{0}$ : Initial hot air temperature, ${ }^{\circ} \mathrm{C}$

$H_{0}$ : Initial hot air humidity content, $\mathrm{Kg}$ (Water). $($ Kg(Air $))^{-1}$

$m_{d}$ : Real-time corn weight in the thin layer box, $\mathrm{Kg}$.

\section{Conflict of Interests}

The authors declare that there is no conflict of interests regarding the publication of this paper.

\section{Acknowledgments}

This work is supported by the Research on Grain Drying Speed Control Model and Intelligent System for Grain Industry Scientific Research in the Public Interest (201313001-07). This work is supported by the planning subject of the twelfth 
five-year-plan in national science and technology for the rural development in China: research and industrialization projects of special intelligent equipment for a variety of food. (2013BAD17B07).

\section{References}

[1] Z. Liu, Z. Wu, Z. Zhang, W. Wu, and H. Li, "Research on online moisture detector in grain drying process based on V/F conversion," Mathematical Problems in Engineering, vol. 2015, Article ID 565764, 10 pages, 2015.

[2] D. Zare and G. Chen, "Evaluation of a simulation model in predicting the drying parameters for deep-bed paddy drying," Computers and Electronics in Agriculture, vol. 68, no. 1, pp. 7887, 2009.

[3] A. Löpez, M. T. Piqué, and A. Romero, "Simulation of deep bed drying of hazelnuts," Drying Technology, vol. 16, no. 3-5, pp. 651665,1998 .

[4] Z. Tang, S. Cenkowski, and W. E. Muir, "Modelling the superheated-steam drying of a fixed bed of brewers' spent grain," Biosystems Engineering, vol. 87, no. 1, pp. 67-77, 2004.

[5] D. Zare, S. Minaei, M. Mohamad Zadeh, and M. H. Khoshtaghaza, "Computer simulation of rough rice drying in a batch dryer," Energy Conversion \& Management, vol. 47, no. 18-19, pp. 3241-3254, 2006.

[6] F. W. Bakker-Arkema, W. G. Bickert, and R. J. Patterson, "Simultaneous heat and mass transfer during the cooling of a deep bed of biological products under varying inlet conditions," Journal of Agricultural Engineering Research, vol. 12, pp. 297-307, 1967.

[7] F. W. Bakker-Arkema, L. E. Lerew, S. F. De Boer, and M. G. Roth, "Grain dryer simulation," Researeh Report 224, Experimental Station, Michigan State University, East Lansing, Mich, USA, 1974.

[8] H. B. Spencer, "A mathematical simulation of grain drying," Journal of Agricultural Engineering Research, vol. 14, no. 3, pp. 226-235, 1969.

[9] J. Woodforde and P. J. Lawton, "Drying cereal grain in beds six inches deep," Journal of Agricultural Engineering Research, vol. 10, no. 2, pp. 146-171, 1965.

[10] R. G. Clark and W. J. Lamond, "Drying wheat in two foot beds I: rate of drying," Journal of Agricultural Engineering Research, vol. 13, no. 2, pp. 141-148, 1968.

[11] R. G. Clark and W. J. Lamond, "Drying wheat in $2 \mathrm{ft}$ beds: III," Journal of Agricultural Engineering Research, vol. 13, no. 4, p. 323, 1969.

[12] J. R. Sharp, "A review of low temperature drying simulation models," Journal of Agricultural Engineering Research, vol. 27, no. 3, pp. 169-190, 1982.

[13] Y. Sun, C. C. Pantelides, and Z. S. Chalabi, "Mathematical modelling and simulation of near-ambient grain drying," Computers and Electronics in Agriculture, vol. 13, no. 3, pp. 243-271, 1995.

[14] V. K. Srivastava and J. John, "Deep bed grain drying modeling," Energy Conversion and Management, vol. 43, no. 13, pp. 16891708, 2002.

[15] G. Xi and W. Li, Physics in Modern Agriculture and Biology, Science and Technology Press, Beijing, China, 2002.

[16] W. Wu, Research on Mechanism and Methods of Corn Drying Quality Control, Jilin University, Chang Chun, China, 2003.
[17] L. Yin, F. Yu, W. Wu, and Z. Ma, “The investigate on mechanism of cryogenic vacuum grain drying," Journal of Chinese Cereals and Oils, vol. 21, no. 5, pp. 129-132, 2006.

[18] L. Yin, Research on Characteristics and Mathematical Models for Corn Low Temperature Vacuum Drying, Jilin University, Chang Chun, China, 2007.

[19] Y. Zhang, W. Wu, H. Zhu, and L. Yin, “The computer numerical simulation of corn vacuum drying heat and mass transfer process," in Proceedings of the IEEE International Conference on Electronics, Communications and Control (ICECC '11), pp. 17001703, IEEE, September 2011.

[20] Z. Xu, Y. Yongguang, Y. Songbo, and W. Wenfu, "Experimental research on moisture migration during rice vacuum drying process based on water potential," Grain and Oil Processing, vol. 10, pp. 110-112, 2007.

[21] C. Yang, Research on Characteristics of High Moisture Corn During Hot Air and Vacuum Combination Drying Process, Jilin University, Changchun, China, 2007.

[22] W. Wu, X. Zheng, and Z. Ma, Grain Drying and Storage Theory and Technology, Jilin Science and Technology Press, Changchun, China, 2001.

[23] C. Cao and W. Zhu, Computer Simulation for the Agricultural Drying Process, China Agriculture Press, Beijing, China, 1999.

[24] D. B. Brooker, F. W. Bakker-Arkema, and C. W. Hall, Drying Cereal Grains, AVI, Westport, Conn, USA, 1974.

[25] J. J. Barker, "Heat transfer in packed beds", Industrial \& Engineering Chemistry, vol. 57, no. 4, pp. 43-51, 1965.

[26] A. W. Aregba and J.-P. Nadeau, "Comparison of two nonequilibrium models for static grain deep-bed drying by numerical simulations," Journal of Food Engineering, vol. 78, no. 4, pp. 1174-1187, 2007.

[27] C. Cao, Q. Liu, and D. Liu, Drying Mechanism, Processes and Technologies of Agricultural Products, China Agricultural University Press, Beijing, China, 1998.

[28] J. Liu, Research on Microcomputer Automatic Monitoring System of Grain Dryers, Northeast Agricultural University, College of Engineering, Harbin, China, 2002.

[29] Z. Naghavi, A. Moheb, and S. Ziaei-rad, "Numerical simulation of rough rice drying in a deep-bed dryer using non-equilibrium model," Energy Conversion and Management, vol. 51, no. 2, pp. 258-264, 2010.

[30] C. Cao, "Mathematical simulation for grain drying," Journal of Beijing Agricultural Mechanization Academy, vol. 8, pp. 79-94, 1984.

[31] J. Li, K. Chen, M. Yang, and C. Ji, "Computer simulation for fixed deep bed rice drying," Journal of Agricultural Machinery, vol. 32, no. 6, pp. 59-62, 2001.

[32] Z. Wu and Y. Cao, Green Ecological Technology for Grain Storage, China Science and Technology Press, Beijing, China, 2011.

[33] X. Li, S. Wang, Y. Zhang, and W. Qin, "Research on corn moisture absorption characteristics and the isotherm type," Journal of Chinese Cereals and Oils, vol. 1, pp. 80-86-96, 2012. 


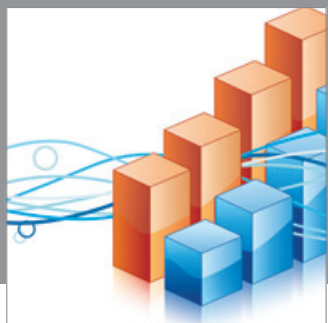

Advances in

Operations Research

mansans

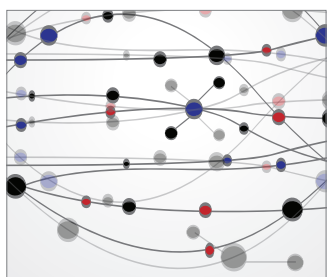

The Scientific World Journal
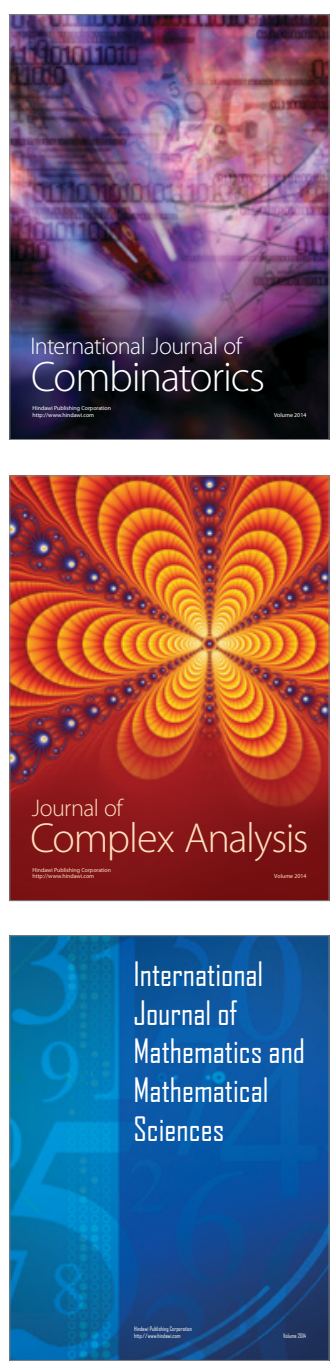
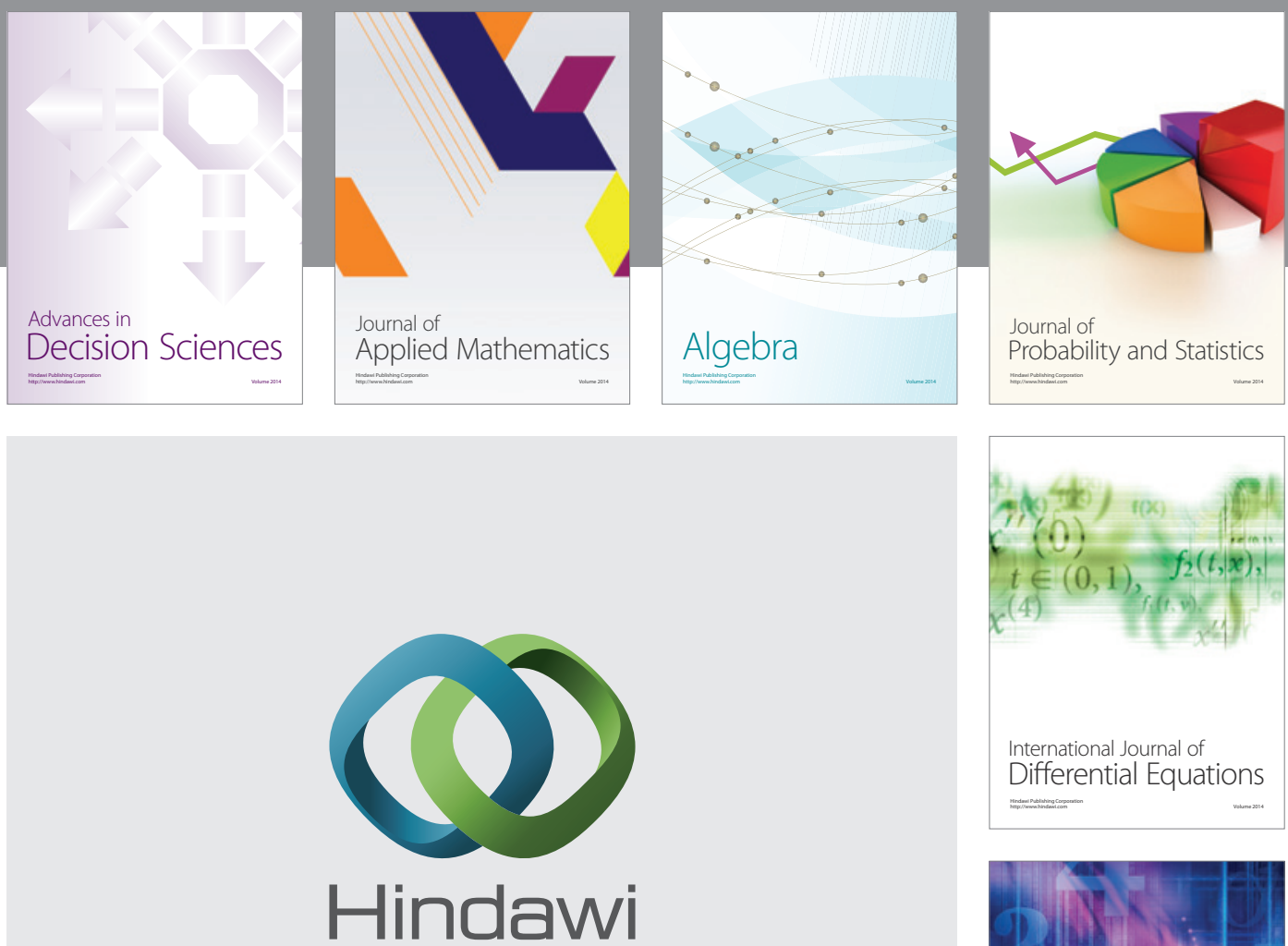

Submit your manuscripts at http://www.hindawi.com
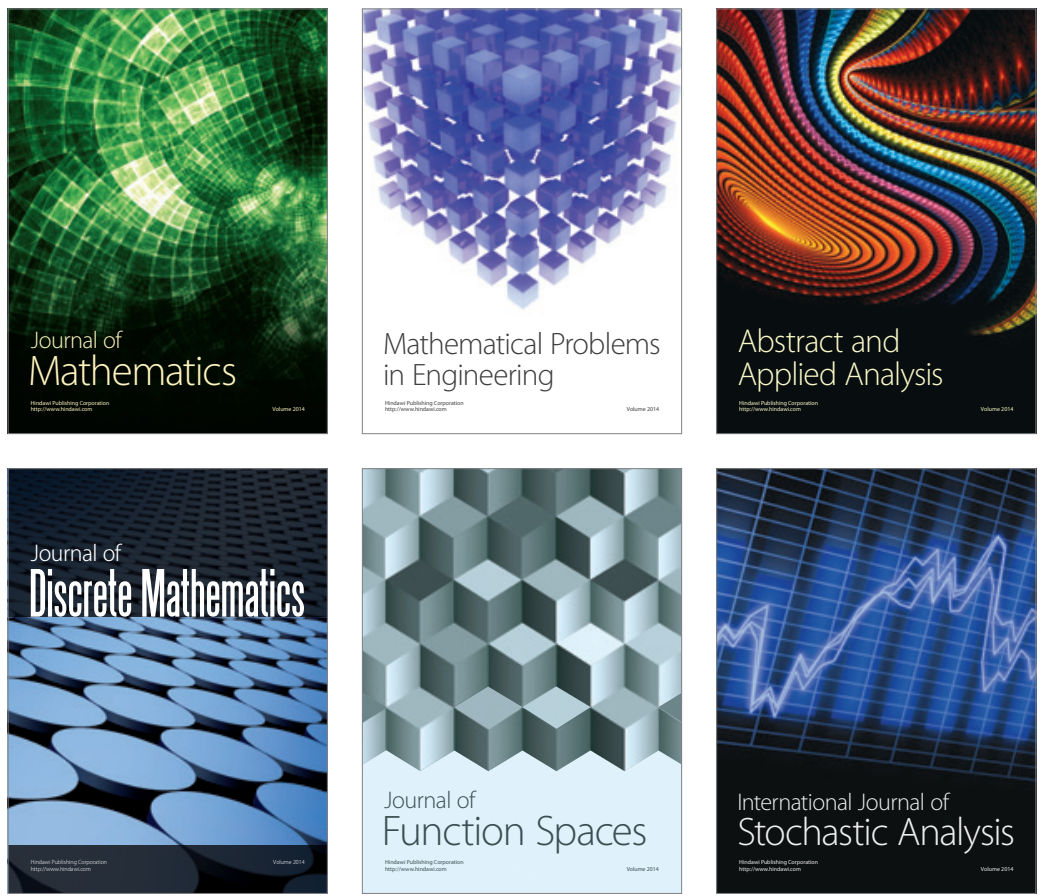

Journal of

Function Spaces

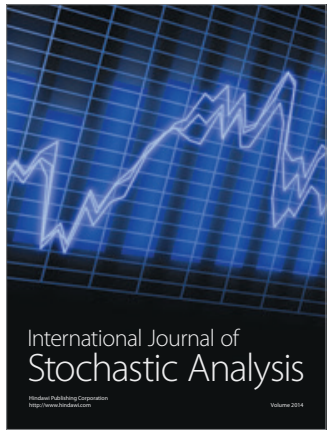

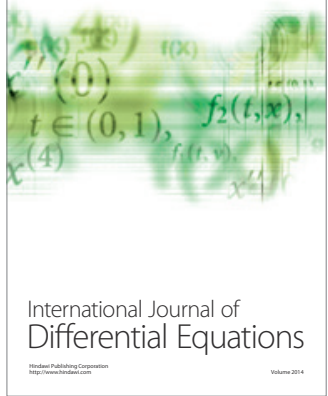
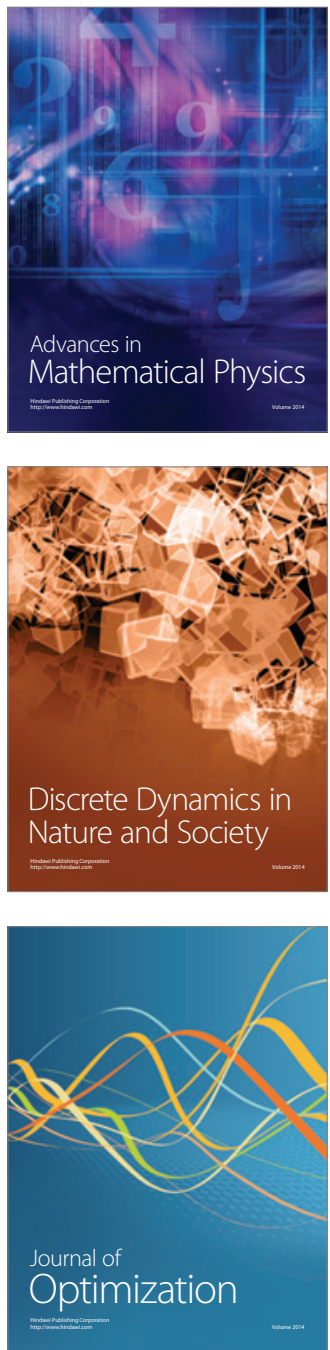